\title{
One hundred years of shared interest
}

\author{
Martin Rossor
}

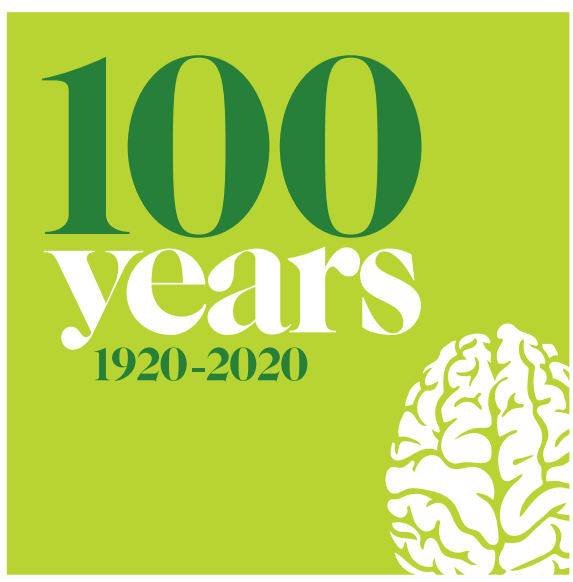

At a time of increasing specialisation in journal publishing it is remarkable that a journal combining neurology and psychiatry has stood the test of time.

At the start of the 20th century, a number of international neurology journals such as Brain in the UK and Neurology and Archives of Neurology in the USA had become well established. Similarly, psychiatry journals such as the Journal of Mental Science were flourishing. However, particularly on the continent where a much closer teaching of neurology and psychiatry had occurred compared with the UK, there were combined neurology and psychiatry journals such as the Dutch Psychiatre en Neurologische Bladen (started in 1897). Considering the tendency in the UK to separate the practice of neurology and psychiatry, it is notable that a combined journal, the Review of Neurology and Psychiatry, was founded in 1902 by Alexander Bruce, Physician to the Edinburgh Royal Infirmary. The first issue included a commentary by Sir John Sibbald, Deputy Commissioner in Lunacy for Scotland on Psychiatry in General Hospitals and speaks to the 'essential unity of the two (neurology and psychiatry ed) subjects'. The Review of Neurology and Psychiatry was continued by Alexander Bruce's son Ninian Bruce but its life was short-lived and it did not resume publication after the end of the First World War. However, in 1920 Kinnier Wilson was appointed

Correspondence to Prof Martin Rossor, Dementia Research Centre, ION, University College London Faculty of Brain Sciences, London, UK; m.rossor@ucl. ac.uk editor of a new publication, The Journal of Neurology and Psychopathology.

It is perhaps unsurprising that Kinnier Wilson should have been chosen as the editor; he had married Alexander Bruce's daughter and it was to his brother-in-law Ninian Bruce that the editorship of the Review of Neurology and Psychiatry had been passed until the outbreak of war. Moreover, Kinnier Wilson had a particular interest in psychological aspects of neurology.

The editorial in the first issue "The realm of neurology" 1 is unsigned but presumably penned by Kinnier Wilson himself.

The truth is, in reality, that the neurologist of today is he who pursues the study of either psychical or physical side, or both, and who has succeeded to an empire wherein is stored the accumulated wealth of knowledge derived and being derived from scientific and clinical research on the part of many differing groups and fellowships of workers. The nervous system still stands as the very core, the hub, of ever-widening theoretical and practical interests. More than ever must the neurologist be a man of culture and of aspiration, a savant in the right sense of the word, who can see his subject whole, and appreciate contributions from whomsoever they come. He boldly takes its vegetative, sensorimotor, and psychical aspects alike for his province and will not relinquish any section of the field to deputies.

This is followed by an editorial entitled "Present position of psychopathology". There is a brief reference to Freud, Jung and Adler that argues for much common ground between the different schools of psychoanalysis, and then goes on to say:

The dispute which has long raged as to whether mental and so-called "functional nervous" disorders are of psychical or physical origin-a dispute which is inevitably sterile-should be replaced by a careful taking into account of the material which every method of approach-chemical, physiological, anatomical, psychological is able to offer, and an attempt to correlate this material into an harmonious whole.
Perhaps the conception which promises the most fruitful line of advance in this direction is that of biological reaction, the view that the field of mental and "nervous" disorders is one in which disease entities in the strict sense of the word cannot profitably be distinguished, but that the clinical pictures encountered are to be regarded as different types of reaction in a psychophysical organism to the environment in which it has to live. In the development of such a conception it may be hoped that all the facts ascertained, whether they be chemical, anatomical, physiological or psychological, will fall into place and be capable of correlation one with another. One of the chief objects of the JOURNAL is to help in this co-ordination and correlation.

These views clearly resonated more generally within the medical profession. In the 24 July issue of the Lancet in $1920^{2}$, only 2 months after the first issue of the Journal of Neurology and Psychopathology, a comment was published entitled "The realm of neurology and psychopathology". The comment discusses the concept of functional nervous disorder and refers to the articles in the first issue of the Journal of Neurology and Psychotherapy 'show what is the editorial mind in embarking on the troubled waters of special journalism' (...) 'the most fruitful line of advance of the present time is that of biological reaction, mental and nervous disorders, not being distinguished as disease entities, but rather as different types of reaction to environment shown by a psychophysical organism'.

The Journal of Neurology and Psychotherapy was originally published in Bristol by John Wright and Sons, although 3 years later the publishing was taken over by William Heinemann (Medical Books) in London before being acquired by the British Medical Association in 1926, under whose aegis the journal has been published ever since. The initial editorial board was divided into neurology and psychopathology sections, although the distinction between these two in the journal frontispiece was dropped after only 4 years (1923-1924). In the year following Kinnier Wilson's death in 1937, the journal appears as the Journal of Neurology and Psychiatry and there 
is a major expansion in the board with addition of many international members such as Denny Brown and by 1944 it had acquired its current name of the Journal of Neurology, Neurosurgery and Psychiatry.

The addition of neurosurgery may have reflected the influence of the Second World War on clinical neuroscience and indeed many articles in the next decade related to neurosurgical aspects and sequelae of head trauma. Similarly, many of the psychiatry papers related to war neuroses. The addition of neurosurgery was timely as the breadth of neurosurgery expanded although the papers were and have remained largely those of clinical series with technical aspects dealt with in specialist journals. The frequency of submissions in psychiatry dwindled in the 1970s and when they picked up in the 1980s and 1990s were in areas of overlap, particularly in relation to cognition and the dementias.

So what of the future, can the JNNP hold the circle around three different areas of clinical practice. For this previous editor the answer is that it is important that it does so. Joseph Martin ${ }^{3}$ nearly 20 years ago ${ }^{3}$ invoked Winston Churchill's characterisation of the USA and Great Britain as two countries separated by a common language, subsequently paraphrased as neurology and psychiatry as being two specialties divided by the same organ. The future of clinical neuroscience will depend on close working of disciplines and in some areas such as cognitive disorders, epilepsy and neuropsychiatry this is often evident but much more can be done in areas such as developmental disorders, head injury an intellectual disability. The JNNP will be important in this joint venture.

Contributors I am the lead or corresponding author of the output.

Funding The author has not declared a specific grant for this research from any funding agency in the public, commercial or not-for-profit sectors.

Competing interests None declared.

Patient consent for publication Not required.

Provenance and peer review Commissioned; internally peer reviewed.
C Author(s) (or their employer(s)) 2020. No commercial re-use. See rights and permissions. Published by BMJ.

D Check for updates

To cite Rossor M. J Neurol Neurosurg Psychiatry 2020;91:225-226.

Received 12 December 2019

Accepted 12 December 2019

\section{SLinked}

http://dx.doi.org/10.1136/jnnp-2019-321938

J Neurol Neurosurg Psychiatry 2020;91:225-226. doi:10.1136/jnnp-2019-321981

ORCID iD

Martin Rossor http://orcid.org/0000-0001-8215-3120

\section{REFERENCES}

1 Anon. Editorial: the realm of Neurology. J Neurol Psychopathol 1920;1:67-9.

2 Anon. The realm of Neurology and psychopathology. Lancet 1920;196:195-6.

3 Martin JB. The integration of Neurology, psychiatry, and neuroscience in the 21st century. Am J Psychiatry 2002;159:695-704. 